\title{
Sistemas de dessecação antecedendo a semeadura direta de milho e controle de plantas daninhas
}

\author{
Desiccation systems prior to no-till corn sowing and weed control
}

\author{
Jamil Constantin ${ }^{\mathrm{I}}$ Rubem Silvério de Oliveira Jr. ${ }^{\mathrm{I}}$ Miriam Hiroko Inoue ${ }^{\mathrm{II}}$ \\ João Guilherme Zanetti de Arantes ${ }^{\mathrm{I}}$ Sidnei Douglas Cavalieri ${ }^{\mathrm{I}}$
}

RESUMO

No sistema de plantio direto, a escolha do momento adequado para a dessecação da cobertura vegetal antecedente à semeadura é fundamental para o êxito da cultura do milho. O objetivo do trabalho foi avaliar os efeitos sobre a cultura do milho de três sistemas de dessecação de manejo antecedendo o plantio direto combinados com três métodos de controle de plantas daninhas, em áreas com alta densidade de infestação de ervas. Os tratamentos foram arranjados em esquema fatorial $(3 \times 3)+1$, em delineamento de blocos casualizados, com cinco repetições. Os três sistemas de dessecação avaliados foram: (1) dessecação de manejo realizada imediatamente antes da semeadura - sistema Aplique-Plante (“AP”); (2) dessecação de manejo realizada sete dias antes da semeadura direta (DAS) ("7 DAS"); e (3) manejo antecipado ("MA"), quando as dessecações foram realizadas aos 25 e 1 DAS do milho. Após a emergência da cultura, as opções de controle foram: (1) nenhum controle de plantas daninhas; (2) capina manual e (3) aplicação de mesotrione + atrazine + óleo mineral em pósemergência, além de uma testemunha sem manejo e sem controle em pós-emergência. Verificou-se que, após a emergência da cultura, a utilização do MA proporcionou maior controle das plantas daninhas, em comparação com os sistemas AP e 7 DAS. Evidenciou-se um atraso de crescimento nas plantas de milho crescidas nas áreas onde foi utilizado o sistema AP. Observou ainda que, independentemente do método de controle de plantas daninhas utilizado em pós-emergência, os maiores rendimentos de grãos de milho ocorreram no MA com ganhos que variaram entre 593 a $1060 \mathrm{~kg} \mathrm{ha}^{-1}$.

Palavras-chave: Zea mays, herbicidas, manejo integrado, plantio direto.

\begin{abstract}
The adequate timing for cover crop management before sowing is fundamental for the success of no-till corn. This research aimed to evaluate the effects on corn growth and yield of three burndown systems before no-till sowing, combined with three weeds control methods after crop emergence, in areas with high density of weeds. Treatments were arranged in a factorial scheme $(3 \times 3)+1$, randomized block design and five replications. The three burndown methods evaluated were: (1) burndown right before crop sowing ("AP”); (2) burndown seven days before crop sowing ("7 DAS"); and (3) antecipated burndown ("MA"), composed of herbicide application, at 25 days and 1 day before crop sowing. After corn emergence, weed control treatments were: (1) no control; (2) manual weeding; and (3) mesotrione + atrazine + mineral oil applied at post-emergence, and an untreated check, with no burndown and no post-emergence weed control. The burndown system MA improved weed control after crop emergence compared to $A P$ and 7 DAS. Delay of corn growth occured in areas where AP burndown was used. Regardless the method of postemergence weed control, the highest grain yields were registered in MA, with gains from 593 to $1060 \mathrm{~kg} \mathrm{ha}^{-1}$.
\end{abstract}

Key words: Zea mays, herbicides, integrated mangement, no till.

\section{INTRODUÇÃO}

Um dos fatores preponderantes na determinação da capacidade competitiva da cultura e

'Departamento de Agronomia, Universidade Estadual de Maringá (UEM). Av. Colombo, 5790 - 87020-900. Maringá, PR, Brasil. E-mail: rsojunior@uem.br. Autor para correspondência.

"Departamento de Agronomia, Universidade do Estado de Mato Grosso (UNEMAT). Rod. MT 358, Km 07, C. Postal 287 78300-000. Tangará da Serra, MT, Brasil. 
das espécies daninhas é a época em que uma emerge em relação à outra. Quanto maior a precocidade de emergência de uma espécie em relação à outra, maiores as chances daquela que emergiu primeiro levar vantagem competitiva (CONSTANTIN, 2001). CALEGARI et al. (1998) relatam que o plantio de milho logo após a dessecação da aveia pode acarretar germinação desuniforme e desenvolvimento inicial inadequado (estiolamento) das plântulas de milho e recomendam um intervalo de pelo menos duas a três semanas entre o manejo da aveia e a semeadura do milho. Os mesmos autores também observaram que determinadas coberturas podem ter efeitos alelopáticos sobre culturas subsequentes. Uma forma de diminuir esses efeitos seria aguardar um tempo maior para implantação do cultivo sobre a cobertura manejada. COWAN et al. (1998) semearam Amaranthus sp. e Echinochloa crus-galli em duas épocas, em relação à soja: simultaneamente e no estádio cotiledonar da cultura. Os resultados que obtiveram demonstraram que não só a densidade, mas principalmente a época de emergência das plântulas de espécies daninhas influenciou a magnitude das perdas de produtividade da cultura. Quando a emergência das plantas daninhas ocorreu após a da cultura, a capacidade competitiva das infestantes foi significativamente reduzida.

A capacidade competitiva da cultura da soja em relação às plantas daninhas é aumentada quando a semeadura é realizada mais próxima à data da dessecação (RIZZARDI et al., 2003). Por outro lado, nas áreas de plantio direto, em que a cobertura vegetal geralmente está em grande quantidade, a dessecação deve ser feita no mínimo 15 a 20 dias antes da semeadura da cultura, a fim de se evitarem possíveis prejuízos à produtividade (CONSTANTIN et al., 2007).

Dentro desse contexto, este trabalho objetivou avaliar a interação entre sistemas de dessecação e métodos de controle de plantas daninhas após a emergência, com relação ao desenvolvimento e rendimento de grãos na cultura do milho.

\section{MATERIAL E MÉTODOS}

O experimento foi conduzido na Fazenda Experimental da COPACOL, localizada em Cafelândia, no Paraná (PR). A área utilizada não foi cultivada na safra de inverno anterior. No momento do início da implantação dos sistemas de manejo, a área apresentava-se com 80 a $100 \%$ de cobertura; cerca de $80 \%$ deste total era composto por Brachiaria plantaginea, Euphorbia heterophylla, Bidens pilosa, Sonchus oleraceus e Amaranthus hibridus.
No experimento, foi utilizada metodologia semelhante à empregada por CONSTANTIN et al. (2007), adequando alguns fatores de acordo com as necessidades locais. $O$ delineamento experimental foi de blocos casualizados, com cinco repetições. As parcelas experimentais tiveram dimensões de 4,0 x 5,0 $\mathrm{m}$, tomando-se como área útil as três linhas centrais, exceto um metro de cada extremidade. Foram avaliados 10 tratamentos, compostos por um esquema fatorial $(3 x 3)+1$. Os fatores foram constituídos por três sistemas de manejo [Aplique-Plante (AP), 7 Dias Antes da Semeadura (7 DAS) e Manejo Antecipado (MA)] e três formas de controle das plantas daninhas após a emergência da cultura (nenhum controle, capina manual das parcelas e aplicação de herbicidas pós-emergência), além de um tratamento adicional constituído por uma testemunha (nenhum tipo de manejo e nenhum tipo de controle em pós-emergência)

No sistema AP, aplicou-se o herbicida para dessecação (1,36 kg ha-1 de glyphosate + 0,024 kg ha-1 de carfentrazone-ethyl $+0,5 \% \mathrm{v} / \mathrm{v}$ de Assist) e efetuouse a semeadura no mesmo dia. No sistema 7 DAS, efetuou-se a dessecação $\left(1,36 \mathrm{~kg} \mathrm{ha}^{-1}\right.$ de glyphosate + $\left.0,67 \mathrm{~kg} \mathrm{ha}^{-1} 2,4-\mathrm{D}\right)$, e a semeadura foi realizada sete dias após. No sistema MA, a dessecação foi realizada em duas etapas: a primeira etapa $\left(1,55 \mathrm{~kg} \mathrm{ha}^{-1}\right.$ glyphosate $\left.+0,67 \mathrm{~kg} \mathrm{ha}^{-1} 2,4-\mathrm{D}\right)$ foi realizada 25 dias antes da semeadura, e a segunda [(diuron+paraquat) $(120+240)$ $\mathrm{g} \mathrm{ha}^{-1}+0,1 \% \mathrm{v} / \mathrm{v}$ de Agral] foi realizada um dia antes da semeadura do milho.

Os tratamentos de controle de plantas daninhas após a emergência do milho, foram: sem nenhum controle de plantas daninhas; capina manual das parcelas e aplicação da mistura de mesotrione (120 $\left.\mathrm{g} \mathrm{ha}^{-1}\right)+$ a mistura atrazine e óleo vegetal [1200+900 g ha $^{-1}$ ] em pós-emergência. A aplicação dos herbicidas em pós-emergência ocorreu em 20/12/2003 (19 dias depois da semeadura - DDS), momento em que a infestação de folhas largas havia atingido o estádio predominante de quatro folhas verdadeiras. Essa aplicação foi realizada simultaneamente nos três sistemas de manejo. As condições climáticas no momento da aplicação foram de $92 \%$ de umidade relativa, $28^{\circ} \mathrm{C}$ de temperatura e solo pouco úmido. Todas as aplicações de herbicidas foram realizadas com um pulverizador costal de pressão constante à base de $\mathrm{CO}_{2}$, equipado com pontas tipo leque XR110.02, pressão de 2,0 $\mathrm{kgf} \mathrm{cm}^{-2}$, proporcionando o equivalente a $200 \mathrm{~L}$ $\mathrm{ha}^{-1}$ de calda.

A semeadura direta do milho ocorreu em 01/ 12/2003, utilizando-se a cultivar '30F90', com espaçamento de $0,90 \mathrm{~m}$ entre linhas e seis sementes por metro linear. A emergência teve início cinco dias 
após a semeadura. A adubação de plantio consistiu em $300 \mathrm{~kg}$ do formulado 08-30-20 por hectare, seguida da aplicação em cobertura de $100 \mathrm{~kg} \mathrm{ha}^{-1}$ de uréia, quando o milho encontrava-se com quatro a seis folhas. Os demais tratos culturais foram feitos segundo as recomendações regionais (IAPAR, 1991).

As características avaliadas nas plantas daninhas incluíram contagens realizadas na véspera da semeadura, aos 38 DDS e nas datas de aplicação dos herbicidas para cada sistema de manejo. Em cada avaliação, foram realizadas 12 amostragens por sistema de manejo ou quatro amostragens por parcela, sendo cada amostragem realizada numa área de 0,5 x 0,5m. Com relação à cultura do milho, foram avaliados os parâmetros: estatura das plantas (altura do solo até a inserção da última folha completamente expandida em 10 plantas por parcela) aos 38 e 52 DDS; teor de umidade dos grãos colhidos (média de duas amostras por parcela); e rendimento de grãos corrigido para $13 \%$ de umidade obtida por meio da colheita de quatro metros lineares centrais de três linhas centrais de cada parcela, convertendo-se posteriormente para $\mathrm{kg} \mathrm{ha}^{-1}$.

Os dados foram submetidos à análise de variância e ao teste de comparação de médias de ScottKnott (5\% de probabilidade), utilizando-se o pacote estatístico SAEG (SAEG, 1997).

\section{RESULTADOSE DISCUSSÃO}

Verificou-se que, para densidade de plantas daninhas (Tabela 1), não houve interação entre sistemas de manejo e as formas de controle. Assim, a densidade de plantas daninhas emergidas foi superior no sistema MA, em relação aos demais sistemas quando avaliada na véspera da semeadura (Tabela 1 ). Tal fato deve-se ao efeito da dessecação antecipada, possibilitando que a cobertura vegetal seja eliminada antes da semeadura e favorecendo a emergência de um novo fluxo de plantas daninhas. Contudo, a aplicação de paraquat+diuron resultou na eliminação da sementeira emergida e, consequentemente, a semeadura foi realizada quando a maioria das plantas daninhas já estava sendo controlada. O manejo 7 DAS resultou em infestação de 99 plantas $\mathrm{m}^{-2}$ na avaliação realizada na véspera da semeadura, o que implica uma elevada competição inicial na cultura. Apesar da elevada infestação na véspera da semeadura no sistema de manejo AP, esta foi eliminada pela dessecação realizada imediatamente antes da semeadura.

A eliminação de um número maior de plantas daninhas antes da instalação da cultura no MA resultou em menores infestações após a emergência do milho (Tabela 1). No momento da aplicação do herbicida pósemergente, havia uma infestação de 156 e 83 plantas daninhas $\mathrm{m}^{-2}$ a menos no MA em comparação com os sistemas AP e 7 DAS, respectivamente. Aos 38 DDS, observa-se que, apesar da aplicação de herbicidas realizada aos 19 DDS, ainda houve um pequeno fluxo de emergência de plantas daninhas. Embora de modo geral esse fluxo tardio não tenha se desenvolvido substancialmente em função do sombreamento imposto pelo milho, mesmo assim essa reinfestação no MA foi inferior em mais de $50 \%$ em relação aos outros dois manejos. Na somatória de todas as contagens, após a emergência do milho, o sistema AP foi o que favoreceu a emergência de um maior número de plantas daninhas. Dessa forma, o MA possibilitou a redução da emergência de plantas daninhas durante o ciclo do milho, evitando interferências precoces e facilitando o controle.

Independentemente do método de controle de plantas daninhas em pós-emergência, as plantas de milho apresentaram maior crescimento aos 38 DDP nos manejos 7 DAS e MA (Tabela 2). De modo geral, a eliminação da interferência das plantas daninhas, quer por meio de capina manual ou pela utilização de controle químico, também propiciou maior altura das plantas de milho nesta data. Comportamento semelhante se repetiu

Tabela 1 - Densidade de plantas daninhas (plantas $\mathrm{m}^{-2}$ ) observada nos diferentes sistemas de manejo avaliada no dia antes da semeadura do milho e em duas ocasiões depois da semeadura da cultura.

\begin{tabular}{|c|c|c|c|c|}
\hline \multirow{2}{*}{ Data contagem } & \multicolumn{4}{|c|}{ Sistemas de manejo } \\
\hline & AP & 7 DAS & MA & $\mathrm{CV}(\%)$ \\
\hline No dia antes da semeadura & $126 \mathrm{~b}$ & $99 \mathrm{c}$ & $145 \mathrm{a}$ & 18 \\
\hline 19 dias após a semeadura (DDS) & 422 a & $349 \mathrm{~b}$ & $266 \mathrm{c}$ & 23 \\
\hline $\begin{array}{l}38 \text { DDS (parcelas que receberam controle químico em } \\
\text { pós-emergência) }\end{array}$ & $44 \mathrm{a}$ & 51 a & $19 \mathrm{~b}$ & 17 \\
\hline Total & 592 a & $499 \mathrm{~b}$ & $430 \mathrm{c}$ & 21 \\
\hline
\end{tabular}

Para cada linha, médias seguidas pelas mesmas letras não diferem entre si pelo teste de agrupamento de Scott-Knott. AP: Aplique-Plante; DAS: Dias antes da semeadura; MA = Manejo antecipado; DDS = Dias depoi s da semeadura.

Ciência Rural, v.39, n.4, jul, 2009. 
Tabela 2 - Altura (cm) de plantas de milho (cultivar '30F90') submetidas a diferentes sistemas de manejo e de controle de plantas daninhas em pós-emergência, em duas datas depois da semeadura do milho (38 e 52 DDS).

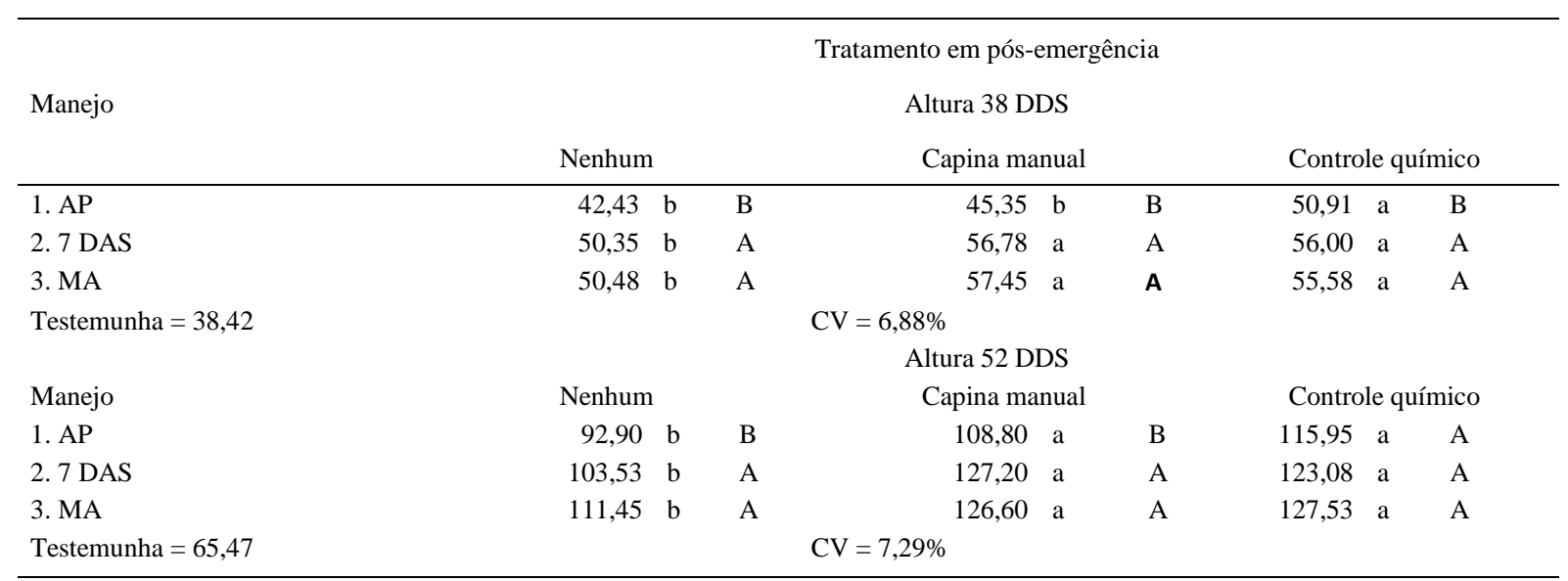

Médias seguidas pelas mesmas letras maiúsculas nas colunas ou minúsculas nas linhas não diferem entre si pelo teste de agrupamento de Scott-Knott. AP: Aplique-Plante; DAS: Dias antes da semeadura; MA = Manejo antecipado; DDS = Dias depois da semeadura.

aos 52 DDP (Tabela 2), quando as plantas das parcelas submetidas ao manejo AP foram menores que as plantas dos demais manejos. O controle das plantas daninhas após a emergência da cultura também influi favoravelmente no crescimento da cultura. Isso demonstra que não houve recuperação do crescimento do milho quando este foi inicialmente afetado. Segundo CALEGARI et al. (1998) e CONSTANTIN et al. (2007), uma possível explicação para tal fato é que a cultura, nas áreas de manejo AP, inicialmente se desenvolveu em condição de grande quantidade de biomassa e de intenso sombreamento, resultando em estiolamento. Dessa forma, houve grande gasto energético no início do ciclo da cultura, com o que pode ter sido comprometido seu desenvolvimento posterior.

Há pesquisas que indicam que a altura de híbridos de milho é uma das características indicadoras da capacidade competitiva da cultura com as plantas daninhas (MOOMAW \& MARTIN, 1984; BEGNA et al., 2001). Plantas de maior altura teriam maior capacidade de sombrear e, portanto, de reduzir não só a capacidade de emergência e crescimento das plantas daninhas, como também a capacidade de produção de diásporos (ROGGENKAMP et al., 2000). Além disso, em milho, uma característica importante na definição do potencial da cultura em competir por luz é a capacidade de interceptação de luz pelas folhas localizadas acima da espiga, levando a cultura a sombrear plantas concorrentes que se posicionam abaixo desse nível (LOOMS et al., 1968). A estatura das plantas de milho demonstra ser uma característica fundamental para definir a competitividade dos genótipos (ROGGENKAMP et al., 2000). Isso explica inclusive o grande efeito depressivo na produção de milho quando este compete com plantas daninhas cujo hábito de crescimento possibilita que estas se desenvolvam mesmo sob baixa intensidade de luz, tais como Datura stramonium (CAVERO et al., 1999). Os resultados obtidos por ARGENTA et al. (2001) sugerem que a redução dos níveis de nitrato e amônio do solo na semeadura realizada imediatamente após a dessecação, devido ao processo de decomposição da palha das plantas daninhas com elevada relação $\mathrm{C} / \mathrm{N}$, poderia ser o fator decisivo para o menor crescimento inicial das plantas de milho no manejo AP, uma vez que a dessecação da cobertura ocorre de forma concomitante à emergência e aos primeiros dias de crescimento da cultura.

Os grãos oriundos de plantas submetidas ao manejo AP apresentaram sempre teores de umidade iguais ou maiores aos grãos dos demais sistemas de manejo (Tabela 3). Tal fato pode estar associado ao desenvolvimento mais lento da cultura nesse sistema, fazendo com que o final do ciclo e consequentemente a perda de água pelos grãos fossem um pouco mais tardios. A implicação prática desse fato é que a colheita seria retardada quando o plantio fosse efetuado em condições de grande cobertura vegetal, pois o desenvolvimento e o ciclo do milho seriam retardados. Contudo, esse efeito significativo no teor de umidade não foi constatado entre os sistemas de manejo avaliados por CONSTANTIN et al. (2007) na cultura do milho.

Os melhores rendimentos de grãos de milho foram observados no MA, para todas as condições de controle de plantas daninhas em pós-emergência 
Tabela 3 - Teor de umidade (\%) de grãos de milho (cultivar '30F90') submetido a diferentes sistemas de manejo e de controle de plantas daninhas em pós-emergência, na data da colheita.

\begin{tabular}{|c|c|c|c|}
\hline \multirow{2}{*}{ Manejo } & \multicolumn{3}{|c|}{----------Tratamento em pós-emergência---------- } \\
\hline & Nenhum & Capina manual & Controle químico \\
\hline 1. AP & 26,47 a $\mathrm{A}$ & 26,40 a $\mathrm{A}$ & 26,20 a $A$ \\
\hline 2. 7 DAS & 25,47 a $\mathrm{B}$ & 25,94 а B & 26,03 a $A$ \\
\hline 3. MA & 25,90 а $B$ & 25,55 а $\mathrm{B}$ & 25,82 a $A$ \\
\hline Testemunha & 26,39 & & \\
\hline CV (\%) & 1,93 & & \\
\hline
\end{tabular}

Médias seguidas pelas mesmas letras maiúsculas nas colunas ou minúsculas nas linhas não diferem entre si pelo teste de agrupamento de Scott-Knott.

(Tabela 4). Avaliando o efeito de diferentes sistemas de manejo sobre o crescimento e o rendimento de grãos de milho, ARGENTA et al. (1999; 2001) observaram que o rendimento da cultura foi influenciado pela época de semeadura do milho após a dessecação da cobertura (aveia-preta), sendo 13,5\% superior quando realizada aos 15 dias após a dessecação em relação à semeadura (um dia após a dessecação). O maior rendimento de grãos obtido com o atraso da época de semeadura do milho foi atribuído a dois fatores: primeiramente devido à drástica redução dos níveis de nitrato e amônio do solo na semeadura realizada um dia após a dessecação, devido ao processo de decomposição da palha de aveia com elevada relação $\mathrm{C} / \mathrm{N}$ e ao aumento da contribuição do $\mathrm{N}$ do solo devido à diminuição da relação $\mathrm{C} / \mathrm{N}$, uma vez que o carbono está sendo perdido na forma de $\mathrm{CO}_{2}$ e o N proveniente dos resíduos da cobertura está sendo conservado pela formação de massa celular microbiana. O MA é o único dentre os sistemas de manejo avaliados que proporciona a emergência do milho num ambiente onde não ocorre a simultaneidade entre a emergência da cultura e a decomposição da massa vegetal que cobre o solo. Esse fato é alcançado por causa da utilização do manejo antecipado em relação à semeadura e da aplicação de um herbicida de contato sobre plantas de pequeno porte no momento da semeadura.

Considerando-se o rendimento de grãos obtido na testemunha (2593kg ha-1) como o potencial mínimo de produção do híbrido utilizado, as condições edafoclimáticas em que o experimento foi conduzido e a produtividade obtida no tratamento MA/Controle químico como sendo $100 \%$ do potencial produtivo desse híbrido sob estas condições, é possível chegar às seguintes conclusões. A primeira é a de que, com a adoção de qualquer sistema de manejo (AP, 7 DAS ou MA), é possível atingir de 60 a 74\% do potencial máximo, mesmo sem adotar nenhuma medida de controle
Tabela 4 - Rendimento de grãos (kg ha ${ }^{-1}$ ) de milho (cv. ‘30F90’), submetido a diferentes sistemas de manejo e de controle de plantas daninhas em pós-emergência. Umidade dos grãos corrigida para 13\%.

\begin{tabular}{lcrr}
\hline \multirow{2}{*}{ Manejo } & \multicolumn{4}{c}{ Tratamento em pós-emergência } \\
\cline { 2 - 4 } & Nenhum & Capina manual & Controle químico \\
\hline 1. AP & 6440 b B & 7873 a B & 7933 a B \\
2. 7 DAS & 6733 b B & 8253 a B & 8386 a B \\
3. MA & 7326 b A & 8893 a A & 8993 a A \\
Testemunha & 2593 & & \\
CV (\%) & 5,17 & & \\
\hline
\end{tabular}

Médias seguidas pelas mesmas letras maiúsculas nas colunas ou minúsculas nas linhas não diferem entre si pelo teste de agrupamento de Scott-Knott.

em pós-emergência. Nesse caso, o ganho em produtividade pela adoção de um sistema mais eficiente no manejo antes da semeadura reflete num ganho mínimo de 14\% de rendimento de grãos. Por outro lado, quando são adotadas medidas de controle das plantas daninhas em pós-emergência, tanto por meio da capina manual, quanto da aplicação de herbicidas, o ganho em rendimento de grãos pela adoção do MA é de $17 \%$, quando este é comparado ao sistema de manejo AP e de 9 a $12 \%$ quando comparado com o sistema de manejo 7 DAS. Por último, a adoção de controle das plantas daninhas após a emergência da cultura representa de 22 a $26 \%$ de aumento no rendimento de grãos do milho, considerando os manejo utilizados. Tais números evidenciam a importância e o significado de um sistema de manejo eficiente na implantação da cultura, uma vez que eventuais perdas no potencial produtivo associado ao início do ciclo do milho não são recuperáveis ao longo do mesmo. Resultados semelhantes foram obtidos em áreas com expressiva cobertura vegetal na região de Campo Mourão, PR (CONSTANTIN et al., 2007).

Ressalta-se que as respostas encontradas neste trabalho restringem-se a áreas com cobertura vegetal acima de 40-50\% da superfície do solo. Em áreas onde existam apenas plantas recém-emergidas ou em pequenas reboleiras, a importância do sistema de manejo no desenvolvimento da cultura torna-se menos evidente.

\section{CONCLUSÃO}

Os sistemas de manejo influenciaram a emergência de plantas daninhas após a emergência do milho, o desenvolvimento e o rendimento de grãos da cultura. O sistema MA possibilitou um melhor desenvolvimento do milho e reduziu a emergência de 
plantas daninhas após a instalação da cultura. As produtividades do milho no MA foram de 9,89 a 17,67 sacos ha-1 superiores aos sistemas de manejo AP e 7 DAS.

\section{REFERÊNCIAS}

ARGENTA, G. et al. Efeitos do manejo mecânico e químico da aveia-preta no milho em sucessão e no controle de capimpapuã. Pesquisa Agropecuária Brasileira, Brasília, v.36, n.6, p.851-860, 2001.

ARGENTA, G. et al. Manejo do nitrogênio em milho em semeadura direta, em dois ambientes. II. Efeito sobre o rendimento de grãos. Ciência Rural, Santa Maria, v.29, n.4, p.587-593, 1999. Disponível em: <http://www.scielo.br/ scielo.php? script=sci_arttext\&pid=S0103$84781999000400002 \& \operatorname{lng}=p t \& n r m=i s o \& t \operatorname{lng}=p t>$. doi: $10.1590 /$ S0103-84781999000400002.

BEGNA, S.H. et al. Morphology and yield response to weed pressure by corn hybrids differing in canopy architecture. European Journal of Agronomy, The Netherlands, Amsterdam, v.14, n.4, p.293-302, 2001.

CALEGARI, A. et al. Culturas, sucessões e rotações. In: Sistema Plantio Direto. O produtor pergunta a Embrapa responde. Dourados: Embrapa-CPAO, 1998. p.59-80. (Coleção 500 perguntas 500 Respostas).

CAVERO, J. et al. Competition between maize and Datura stramonium in an irrigated field under semi-arid conditions. Weed Research, Oxford, v.39, n.3, p.225240, 1999.
CONSTANTIN, J. Métodos de manejo. In: OLIVEIRA JR., R.S.; CONSTANTIN, J. Plantas daninhas e seu manejo. Guaíba: Agropecuária, 2001. p.103-121.

CONSTANTIN, J. et al. Interação entre sistemas de manejo e controle de plantas daninhas em pós-emergência afetando o desenvolvimento e a produtividade do milho. Planta Daninha, Viçosa, v.25, n.3, p.513-520, 2007.

COWAN, P. et al. Interference between pigweed (Amaranthus spp.), barnyardgrass (Echinochloa crus-galli), and soybean (Glycine max). Weed Science, Champaign, v.46, n.5, p.533539, 1998.

IAPAR - Fundação Instituto Agronômico do Paraná. A cultura do milho no Paraná. Londrina: IAPAR, 1991. 271p. (IAPAR, Circular, 68).

LOOMS, R.S. et al. Quantitative descriptions of foliage display and light absorption in field communities of corn plants. Crop Science, Madison, v.8, n.1, p.352-356, 1968.

MOOMAW, R.S.; MARTIN, A.R. Cultural practices affecting season-long weed control in irrigated corn (Zea mays). Weed Science, Champaign, v.32, n.4, p.460-467, 1984.

RIZZARDI, M.A. et al. Ajuste de modelo para quantificar o efeito de plantas daninhas e a época de semeadura no rendimento de soja. Pesquisa Agropecuária Brasileira, Brasília, v.38, n.1, p.35-43, 2003.

ROGGENKAMP, G.J. et al. Velvetleaf (Abutilon theophrasti) and green foxtail (Setaria viridis) response to corn (Zea mays) hybrids. Weed Technology, Lawrence, v.14, n.2, p.304-311, 2000.

SAEG - Sistema para Análises Estatísticas, versão 7.0. Viçosa: Fundação Arthur Bernardes, 1997. 